\title{
Hallucinosis in idiopathic Parkinson's disease
}

\author{
Jacqueline M Graham, Richard A Grünewald, Harvey J Sagar
}

University of Sheffield, Department of Clinical Neurology, N Floor, Royal Hallamshire Hospital, Glossop Road, Sheffield

S10 2JF, UK

J M Graham

R A Grünewald

H J Sagar

Correspondence to: Miss JM Graham, University of Sheffield, Department of Clinical Neurology, N Floor, Royal Hallamshire Hospital, Glossop Road, Sheffield S10 2JF, UK.

Received 21 January 1997 and in revised form 13 May 1997

Accepted 5 May 1997

\begin{abstract}
Background-Hallucinosis is a complication of the treatment of idiopathic Parkinson's disease commonly thought to afflict older, chronically medicated, cognitively impaired patients. However, patients with idiopathic Parkinson's disease of short duration experiencing hallucinosis on relatively low doses of dopaminergic medication have been found. The aim, therefore, was to investigate the homogeneity of a population of patients with idiopathic Parkinson's disease and hallucinosis.

Methods-The clinical, demographic, and cognitive correlates of hallucinosis were investigated in a sample of 129 patients with idiopathic Parkinson's disease.

Results-There were two subgroups of patients with idiopathic Parkinson's disease experiencing hallucinosis. In patients with a disease duration of five years or less, hallucinosis was associated with rapid progression of the motor component of the disease but not cognitive impairment. In patients with idiopathic Parkinson's disease of longer than five years duration, hallucinosis was associated with postural instability, global cognitive impairment, and lack of depressive affect. In all patients with idiopathic Parkinson's disease, hallucinosis was more prevalent when they were treated with a direct acting dopamine receptor agonist. Hallucinosis was not associated with age at onset of idiopathic Parkinson's disease or dosage of dopaminergic medication.

Conclusion-Hallucinosis in idiopathic Parkinson's disease is heterogeneous, falling into two groups. The difference in the pathophysiological basis of hallucinosis in these two groups of patients is discussed.
\end{abstract}

(F Neurol Neurosurg Psychiatry 1997;63:434-440)

Keywords: Parkinson's disease; hallucinosis

Neuropsychiatric complications which occur during the treatment of idiopathic Parkinson's disease include vivid dreaming, illusions, hallucinosis, delusional syndromes, and non-confusional and confusional psychoses. The clinical management of these phenomena is complicated by the adverse motor effects of neuroleptic medication. Patients may have to accept a reduction in dopaminergic medication to relieve psychosis at the expense of mobility.

About $30 \%$ of patients with idiopathic Parkinson's disease will experience hallucinosis during dopaminergic treatment. ${ }^{1}$ The hallucinations are predominantly visual although an auditory component is not uncommon. ${ }^{2}$ Often reported are fully formed non-threatening images of people and animals, often at night, on a background of a clear sensorium and stereotyped for the patient. ${ }^{13-4}$ Illusions seem to occur less often, in about $6 \%$ of treated patients. ${ }^{4}$ Delusions occur in about $3 \%$, are usually paranoid, occur on a background of a clear sensorium, ${ }^{5}$ and commonly have themes of spouse infidelity or family and physician conspiracy. ${ }^{6}$ Vivid dreaming often precedes or coexists with hallucinosis, illusions, and delusions. $^{4} 7$

All dopaminergic medications may evoke hallucinosis but there is dispute over which class of medication is the most likely to do so. ${ }^{1}$ An association between cognitive impairment and hallucinosis has been found in some studies, ${ }^{89}$ but not others. ${ }^{10-12}$

Hallucinosis is commonly assumed to complicate the later stages of idiopathic Parkinson's disease when dopaminergic drug treatment has been given for an extended period and high dosage is required to control motor symptoms. $^{31314}$ This study was initiated as a result of our finding of patients with idiopathic Parkinson's disease of short duration experiencing hallucinosis on relatively low dosages of dopaminergic medication. We have therefore analysed the nature of hallucinosis typically found in idiopathic Parkinson's disease to identify demographic features, clinical features, and aspects of cognitive function which distinguish patients with and without hallucinosis.

\section{Patients and methods}

PATIENTS

Outpatients with idiopathic Parkinson's disease who attended the Royal Hallamshire Hospital's movement disorders clinic between 1994 and 1996 were contacted. Of those $129(88.4 \%)$ participated. All patients fulfilled the Parkinson's Disease Society brain bank clinical diagnostic criteria for idiopathic Parkinson's disease. $^{15}$

\section{MEASURES}

Included were measures of movement, cognition, and affect including some subtests from the Cambridge neuropsychological test automated battery (CANTAB).

\section{Motor function}

The Unified Parkinson's disease rating scale $\left(\mathrm{UPDRS}^{16}\right.$ ) motor subscale rates the severity of motor symptoms in idiopathic Parkinson's disease overall and for each side of the body separately, including measures of tremor, rigidity, 
and bradykinesia. Finger dexterity was assessed by the alternate finger tapping test (AFT) in which the number of alternate taps on two keys, each assigned to a different finger of one hand, was counted for a 30 second period. The mobility measures were determined in the "on" state.

\section{Mood and affect}

Severity of depressive symptomatology was determined from the Beck depression inventory $\left(\mathrm{BDI}^{17}\right)$.

\section{Global cognitive function}

Premorbid intelligence was assessed using the full scale IQ score of the national adult reading test $\left(\mathrm{NART}^{18}\right)$. The Blessed dementia scale information-memory-concentration test $\left(\mathrm{BDS}^{19}\right)$ provided a global measure of cognitive function.

\section{Language}

The letter fluency assessment $\left(\mathrm{LF}^{20}\right)$ required the production of words beginning with a designated letter-F, A, and S-within a 60 second period. Proper nouns and derivatives were not permitted.

\section{Memory and executive function}

The CANTAB pattern and spatial recognition memory subtest ( $\left.P R, S^{21}\right)$ evaluated the ability to discriminate familiar from unfamiliar patterns and spatial positions. Working memory assessments included the CANTAB spatial working memory subtest $\left(\mathrm{SWM}^{22}\right)$ and the digit ordering paradigm $\left(\mathrm{DO}^{23}\right)$. The SWM requires the retention and manipulation of spatial information during a visual search task. In the DO task, subjects hear seven random single digits and are required to put the digits into numerical order. Executive function was also determined using the CANTAB attentional set shifting subtest $\left(\mathrm{SS}^{24}\right)$. There were nine shifts in total and scoring depended upon the number of shifts completed.

\section{Demographics}

Details of age at onset of disease, disease duration, dopaminergic medications, and the presence of complications including response fluctuations, dyskinesiae, falls, and postural instability were recorded. The UPDRS activities of daily living section (UPDRS ADL) was modified into a self report format and included at the end of the questionnaire to provide an indication of the degree to which idiopathic Parkinson's disease interfered with daily functioning.

Table 1 Demographic comparisons of hallucinators and non-hallucinators

\begin{tabular}{llll}
\hline & $\begin{array}{l}\text { Hallucinators } n=32 ; \\
\text { Mean }(S D)\end{array}$ & $\begin{array}{l}\text { Non-hallucinators } n=97 ; \\
\text { Mean }(S D)\end{array}$ & $\chi^{2} / t$ value \\
\hline Sex & 14 female & 46 female & 0.025 \\
Age at onset (y) & $56.6(11.4)$ & $55.2(11.3)$ & 0.59 \\
Disease duration (y) & $9.4(7.3)$ & $6.6(5.5)$ & $1.97\left({ }^{\star}\right)$ \\
\hline
\end{tabular}

(*) $\mathrm{P}<0.10$, approaching significance.

\section{Psychosis questionnaire}

The presence of hallucinations, delusions, and paranoia was determined from self response to the following three questions:

"Have you ever seen or heard things which were not actually there"(hallucinosis)?

"Have you ever had any ideas which you strongly believed in but which your family and friends insisted were false" (delusions)?

Have you ever felt threatened by certain people (or things) who previously had caused you no anxiety" (paranoia)?

\section{PROCEDURE}

The assessment battery was conducted in a single session lasting two to three hours, at either the University of Sheffield Department of Clinical Neurology or at the patients' home. Patients who had experienced hallucinosis were asked to describe their experiences in a semistructured interview, conducted either at the time of assessment or over the telephone. Each experience was categorised according to whether it was illusory ("misperception" of an actual physical stimulus) or hallucinatory (perceptual experience which occurs in the absence of a physical stimulus for that sensory modality), according to the modality in which it occurred, according to whether it was fully formed or vague, according to whether fear was felt, and according to whether the experience occurred on a background of a clear sensorium. If the experience was visual it was determined whether movement was present or not. The dosages of all dopaminergic medications at the time of initial and subsequent hallucinosis were recorded and cross checked, where possible, with the hospital records.

\section{STATISTICAL ANALYSIS}

Hallucinosis and illusions were not analysed separately with respect to the clinical and cognitive variables and the term "hallucinosis" refers to both true hallucinations and illusions. Comparisons between scores were made using $t$ tests for two independent samples and, where appropriate, the Bonferroni correction was applied familywise. The $\chi^{2}$ test with Yate's correction was used for comparisons of categorical data.

\section{Results}

In response to the question "Have you ever seen or heard things which were not actually there"? 32 patients indicated they had experienced hallucinosis and 97 had never hallucinated. Table 1 shows that the patients with and without hallucinosis did not differ in sex distribution $\left(\chi^{2}=0.025, P<0.90\right)$ or age at onset of disease $(t=0.59, \mathrm{P}<0.55)$. There was a trend toward greater prevalence of hallucinosis in patients with longer duration of disease, but this did not reach significance $(t=1.97, \mathrm{P}<0.06)$.

\section{DESCRIPTIVES}

Of the 32 hallucinators, four $(12.5 \%)$ experienced illusions only, $21(65.6 \%)$ experienced hallucinations only, and seven $(21.9 \%)$ experienced both illusions and hallucinations. The experiences of 30 patients $(93.8 \%)$ had a visual 
component, of which $17(53.1 \%)$ occurred only in the visual modality, and $13(43.3 \%)$ occurred with a secondary auditory component. Only two patients $(6.7 \%)$ experienced pure auditory hallucinations. Fear was reported in response to the hallucinosis in six patients $(21.4 \%, \mathrm{n}=28)$ and hallucinosis occurred with retained insight in $19(70.4 \%$, $\mathrm{n}=27$ ).

The illusions and hallucinations were often fully formed images of people, small animals, or insects as illustrated by the following cases:

Case 1

A 62 year old man with idiopathic Parkinson's disease of 24 years duration was taking levodopa, bromocriptine, and pergolide. Hallucinations initially consisted of strangers standing in the doorways or walking through the room and then fading. The strangers seemed to be real people of normal height and dress who were non-threatening and never made a sound. The hallucinations stopped for 18 months before recurring with a change of content. The hallucinations then involved 2-3 inch bat-like creatures flying across the room about every 10 minutes and fading before reaching the wall. Illusions were also present of three dimensional people within the patterned wallpaper including an old gentleman with white hair and a moustache, a lady in a pink hat, and a row of Indians with white helmets carrying shields and swords.

Case 2

A 63 year old woman with idiopathic Parkinson's disease of six years duration, was taking levodopa and bromocriptine. Auditory hallucinosis, in the form of indistinct voices talking loudly outside the window, often occurred after she awoke during the night. Illusions of groups of people sitting in the gardens of neighbouring properties were experienced. The people were strangers and varied in group size and position in the garden. According to the spouse, bushes and shrubs were perceived in an altered form.

\section{Case 3}

A 66 year old woman with idiopathic Parkinson's disease of 15 years duration was taking levodopa. Various illusions were experienced on the patterned carpet including maggots writhing, snakes, and worm casts. Hallucinations of a kitten and a rabbit occurred in the car. In the evenings, silent strangers appeared in the living room, did not move, and vanished if approached. Piles of unfamiliar shoes and stockings appeared on the floor and seemed to dissolve when approached.

Case 4

A 55 year old woman with idiopathic Parkinson's disease of one year duration was taking levodopa. At night hallucinations of living friends and relatives including grandchildren, children, and parents occurred in the bedroom. The visions were silent, still, and tended to disappear when touched.

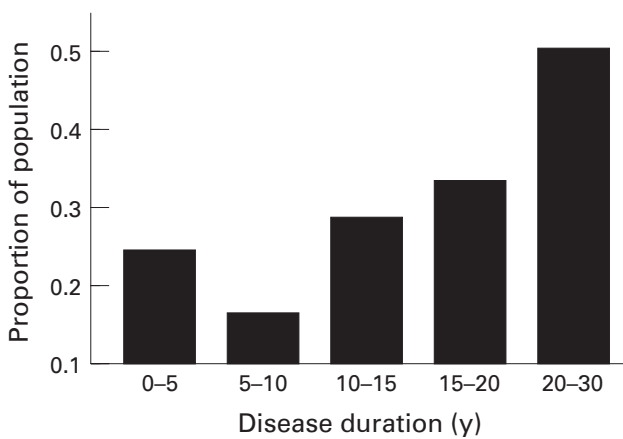

Figure 1 Prevalence of onset of hallucinosis by duration of idiopathic Parkinson's disease.

\section{Case 5}

A 71 year old woman with idiopathic Parkinson's disease of 15 years duration was taking levodopa and bromocriptine. Hallucinations of miniature people and domestic animals were experienced in the daylight or by electric light. The figures were non-threatening, laughed and talked among themselves, and had a male leader who organised them into purposeful activities. Hallucinations of beetles crawling over the body or on the clothes of others also occurred.

Nine $(7.2 \%)$ patients had experienced delusions; of these, seven $(77.8 \%)$ had also experienced hallucinosis.

All delusions were paranoid in nature as illustrated by the following case.

\section{Case 6}

A 71 year old woman with idiopathic Parkinson's disease of 12 years duration was taking levodopa and pergolide. Delusions included the belief that a relative had sold the house leaving the patient homeless, the belief that several thousand pounds had been won but was being withheld, and the belief that a close relative was being unfaithful to her spouse.

\section{DURATION OF DISEASE}

Figure 1 shows the prevalence of onset of hallucinosis by duration of idiopathic Parkinson's disease plotted to investigate the trend toward longer duration of disease in the hallucinating patients. There was a peak in onset of hallucinosis within the first five years of symptoms of idiopathic Parkinson's disease superimposed on an increasing frequency of onset of hallucinosis with greater duration of disease. Patients who experienced their first hallucination within the first five years of idiopathic Parkinson's disease were compared with patients of an equivalent duration of disease who had never hallucinated. Similarly, patients who experienced their first hallucination after five years of idiopathic Parkinson's disease were compared with patients of an equivalent duration of disease who had never hallucinated. Six hallucinators were excluded from the analysis involving the cognitive and motor variables because initial hallucinosis occurred over two years from the time of data collection. 
Table 2 Clinical and cognitive comparisons of early hallucinators and non-hallucinators

\begin{tabular}{|c|c|c|c|}
\hline & $\begin{array}{l}\text { Early hallucinators } \\
(n=13)\end{array}$ & $\begin{array}{l}\text { Early non-hallucinators } \\
(n=54)\end{array}$ & Statistic \\
\hline & Mean (SD) & Mean (SD) & $t$ Value \\
\hline Age at onset $(y)$ & $62.3(8.8)$ & $59.3(11.0)$ & 0.94 \\
\hline NART IQ & $108.6(7.5)$ & $111.7(8.8)(n=53)$ & 1.17 \\
\hline Dose levodopa (mg) & $457(289)(n=7)$ & $433(198)(n=24)$ & 0.25 \\
\hline Dose DA agonist (mg) & $2.22(2.79)(\mathrm{n}=8)$ & $2.32(1.62)(\mathrm{n}=9)$ & 0.09 \\
\hline Number of drugs & $1.33(0.49)(\mathrm{n}=12)$ & $0.86(0.60)(n=52)$ & $2.53^{\star}$ \\
\hline UPDRS ADL & $18.1(10.3)$ & $11.4(8.0)$ & 2.55 \\
\hline UPDRS motor & $29.8(10.8)$ & $22.4(12.7)$ & 1.94 \\
\hline AFT right & $83.2(45.8)(n=11)$ & $71.7(25.7)(n=49)$ & 0.80 \\
\hline AFT left & $63.3(30.1)(\mathrm{n}=11)$ & $71.8(26.2)(\mathrm{n}=50)$ & 0.95 \\
\hline BDI & $13.4(7.7)$ & $9.9(7.6)$ & 1.50 \\
\hline BDS & $5.3(4.8)$ & $2.1(2.8)$ & 2.30 \\
\hline LF & $9.4(5.0)$ & $10.9(4.8)$ & 0.96 \\
\hline DO & $47.4(24.8)$ & $61.9(23.6)$ & 1.98 \\
\hline PR & $18.5(3.4)$ & $19.6(3.1)$ & 1.10 \\
\hline SR & $13.4(2.5)$ & $14.2(2.6)$ & 0.97 \\
\hline SS & $6.5(3.2)$ & $8.1(1.8)$ & 1.82 \\
\hline SWM level 6 between errors & $16.8(9.8)$ & $14.0(8.8)$ & 1.01 \\
\hline SWM level 8 between errors & $34.6(15.1)(n=12)$ & $30.1(13.4)$ & 1.04 \\
\hline Duration IPD at falls (y) & $0.88(0.7)(n=6)$ & $1.17(1.14)(\mathrm{n}=13)$ & 0.58 \\
\hline Duration IPD at fluctuation (y) & $0.29(0.76)(\mathrm{n}=7)$ & $1.27(1.28)(\mathrm{n}=12)$ & $2.11^{\star}$ \\
\hline \multirow[t]{2}{*}{ Duration IPD at dyskinesia (y) } & $0.67(0.76)(\mathrm{n}=3)$ & $2.15(1.75)(\mathrm{n}=5)$ & 1.36 \\
\hline & No (\%) & No $(\%)$ & $\chi^{2}$ Value \\
\hline Sex & 6 female & 29 female & 0.032 \\
\hline Loss of balance & $8(61.5)$ & $25(46.3)$ & 0.46 \\
\hline Tendency to fall & $6(46.2)$ & $13(24.1)$ & 1.545 \\
\hline Fluctuations & $8(61.5)$ & $13(24.1)$ & $5.204^{\star}$ \\
\hline Dyskinesiae & $4(30.8)$ & $5(9.3)$ & $3.004+$ \\
\hline Levodopa & $8(53.3)(n=15)$ & $24(47.1)(n=51)$ & 0.166 \\
\hline Pergolide & $6(40.0)(n=15)$ & $7(13.7)(n=51)$ & $5.078^{\star}$ \\
\hline Bromocriptine & $0(n=15)$ & $2(3.8)(n=53)$ & \\
\hline DA agonist & $6(40.0)(n=15)$ & $9(17.6)(n=51)$ & 3.295 \\
\hline Anticholinergics & $1(7.7)$ & 0 & \\
\hline Selegiline & $3(23.1)$ & $8(15.1)(n=53)$ & 0.077 \\
\hline Apomorphine & 0 & 0 & \\
\hline Untreated & 0 & $13(24.5)(n=53)$ & $3.101 \dagger$ \\
\hline
\end{tabular}

$\star \mathrm{P}<0.05 ; \dagger \mathrm{P}<0.10$, approaching significance.

PATIENTS WITH ONSET OF HALLUCINATIONS WITHIN THE FIRST FIVE YEARS OF SYMPTOMS (EARLY HALLUCINATORS)

Table 2 shows the results of all statistical comparisons between early hallucinators and nonhallucinators. The early hallucinators and nonhallucinators did not differ in sex distribution $\left(\chi^{2}=0.032, \mathrm{P}<0.90\right)$, age at disease onset $(t=0.94, \mathrm{p}<0.35)$ and premorbid intelligence $(t=1.17, \mathrm{P}<0.25)$. The groups were similar on all measures of cognitive and motor mobility when "on".

The presence of disease motor complications and the duration of idiopathic Parkinson's disease at the onset of these complications was compared in the early hallucinators and

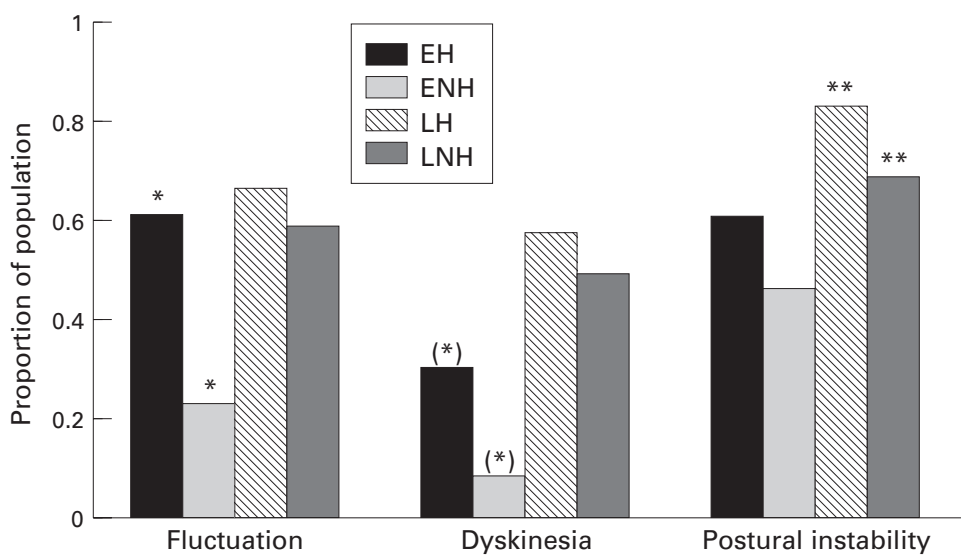

Figure 2 Prevalence of response fluctuation, dyskinesia, and postural instability. EH=early hallucinators; $E N H=$ early non-hallucinators; $L H=$ late hallucinators; $L N H=l a t e$ non-hallucinators. $\left(\left(^{\star}\right) P<0.10 ;{ }^{\star} P<0.05 ;{ }^{\star}{ }^{\star} P<0.01\right)$.

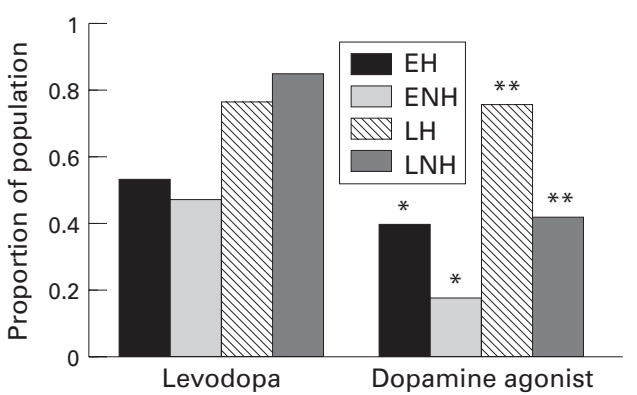

Figure 3 Prevalence of levodopa and dopamine agonist treatment. $E H=$ early hallucinators; $E N H=$ early non-hallucinators; $L H=$ late hallucinators; $L N H=$ late non-hallucinators. $\left({ }^{\star} P<0.10 ;{ }^{\star} P<0.05\right)$.

non-hallucinators. The time from idiopathic Parkinson's disease onset to the onset of response fluctuations was significantly shorter for the hallucinators than the non-hallucinators $(t=2.11, \mathrm{P}<0.05)$. Figure 2 shows that the hallucinators experienced significantly more response fluctuations than the non-hallucinators $\left(\chi^{2}=5.20, P<0.05\right)$ and that there was a trend towards more involuntary movements in the hallucinators $\left(\chi^{2}=3.00, P<0.10\right)$.

The early hallucinators were medicated with a significantly greater number of dopaminergic drugs than the early non-hallucinators $(t=2.53$, $\mathrm{P}<0.014$ ), who tended to be unmedicated more often than the early hallucinators $\left(\chi^{2}=3.10, P<0.10\right)$. The proportion of patients taking each class of dopaminergic medication was compared between hallucinators and nonhallucinators. Anticholinergic drugs, apomorphine, and bromocriptine were prescribed too infrequently to analyse separately and are reported in table 2 . The proportion of patients taking levodopa $\left(\chi^{2}=0.17, \mathrm{P}<0.75\right)$ and selegiline $\left(\chi^{2}=0.08, \quad \mathrm{P}<0.90\right)$ did not differ between those with and without hallucinosis. Figure 3 shows that a greater proportion of hallucinators tended to be medicated with a direct acting dopamine agonist (pergolide or bromocriptine) than the non-hallucinators $\left(\chi^{2}=3.30, P<0.10\right)$, a difference which became significant when the direct acting dopamine agonist pergolide was considered alone $\left(\chi^{2}=5.08, P<0.05\right)$. Early hallucinators and non-hallucinators did not differ in the daily dose of either levodopa $(t=0.25, \mathrm{P}<0.80)$ or direct acting dopamine agonist medications $(t=0.09, \mathrm{P}<0.93)$.

PATIENTS WITH ONSET OF HALLUCINOSIS AFTER FIVE YEARS OF SYMPTOMS (LATE HALLUCINATORS)

Table 3 shows the results of all statistical comparisons between late hallucinators and nonhallucinators. The late hallucinators and nonhallucinators did not differ with respect to sex distribution $\left(\chi^{2}=0.006, \mathrm{P}<0.95\right)$, age at disease onset $(t=0.74, \mathrm{P}<0.46)$, and premorbid IQ $(t=0.68, \mathrm{P}<0.50)$.

The late hallucinators and non-hallucinators were compared on all measures of cognitive and motor mobility when "on". No group differences were detected on any of the mobility measures but the late hallucinators were significantly more impaired in global cognitive 
Table 3 Clinical and cognitive comparisons of late hallucinators and non-hallucinators

\begin{tabular}{|c|c|c|c|}
\hline & $\begin{array}{l}\text { Late hallucinators } \\
(n=13)\end{array}$ & $\begin{array}{l}\text { Late Non-hallucinators } \\
(n=42)\end{array}$ & Statistic \\
\hline & Mean (SD) & Mean (SD) & $t$ Value \\
\hline Age at onset (y) & $52.0(10.7)$ & $50.0(9.5)$ & 0.62 \\
\hline Nart IQ & $108.3(6.1)(\mathrm{n}=11)$ & $110.9(8.7)$ & 0.95 \\
\hline Dose levodopa (mg) & $614(433)(n=14)$ & $667 \mathrm{mg}(286)(\mathrm{n}=35)$ & 0.50 \\
\hline Dose DA agonist (mg) & $3.06(1.76)(n=11)$ & $3.11 \mathrm{mg}(1.85)(\mathrm{n}=18)$ & 0.07 \\
\hline Number of drugs & $2.0(0.82)$ & $1.83(0.70)$ & 0.72 \\
\hline UPDRS ADL & $23.2(7.4)$ & $17.8(8.2)$ & 2.03 \\
\hline UPDRS motor & $32.3(14.5)$ & $26.1(12.2)$ & 1.48 \\
\hline AFT right & $77.1(48.3)(\mathrm{n}=8)$ & $73.6(31.0)(\mathrm{n}=30)$ & 0.25 \\
\hline AFT left & $64.6(43.7)(\mathrm{n}=8)$ & $69.4(23.0)(n=29)$ & 0.30 \\
\hline BDI & $8.4(2.9)(n=11)$ & $13.0(7.9)$ & $3.06^{\star}$ \\
\hline BDS & $6.3(8.1)$ & $2.0(3.0)$ & $2.80^{\star}$ \\
\hline LF & $8.7(2.7)(\mathrm{n}=11)$ & $12.2(3.9)$ & $2.81^{\star}$ \\
\hline $\mathrm{DO}$ & $47.1(25.4)(n=11)$ & $62.6(19.9)$ & 2.17 \\
\hline PR & $17.9(3.6)(n=11)$ & $19.6(2.6)(n=41)$ & 1.76 \\
\hline SR & $12.9(2.8)(\mathrm{n}=11)$ & $14.4(2.8)(\mathrm{n}=40)$ & 1.56 \\
\hline sS & $6.1(4.1)(n=11)$ & $7.6(2.6)(\mathrm{n}=41)$ & 1.18 \\
\hline SWM level 6 between errors & $17.6(7.3)(\mathrm{n}=10)$ & $13.5(8.2)(\mathrm{n}=41)$ & 1.45 \\
\hline SWM level 8 between errors & $34.3(11.7)(\mathrm{n}=10)$ & $30.3(10.2)(n=40)$ & 1.10 \\
\hline Duration IPD at falls (y) & $6.50(4.85)(n=6)$ & $7.10(5.22)(\mathrm{n}=17)$ & 0.25 \\
\hline Duration IPD at fluctuation (y) & $7.72(5.50)(\mathrm{n}=9)$ & $5.77(5.1)(n=24)$ & 0.96 \\
\hline \multirow[t]{2}{*}{ Duration IPD at dyskinesia (y) } & $5.79(3.24)(\mathrm{n}=7)$ & $9.14(5.05)(\mathrm{n}=19)$ & 1.63 \\
\hline & No (\%) & No (\%) & $\chi^{2}$ value \\
\hline Sex & 6 female & 21 female & 0.006 \\
\hline Loss of balance & $10(83.3)$ & $29(69)$ & $10.547^{\star \star}$ \\
\hline Tendency to fall & $5(41.7)$ & $21(50)$ & 0.033 \\
\hline Fluctuations & $8(66.7)$ & $25(59.5)$ & 0.013 \\
\hline Dyskinesiae & $7(58.3)$ & $21(50)$ & 0.033 \\
\hline Levodopa & $13(76.5)(n=17)$ & $36(85.7)$ & 0.737 \\
\hline Pergolide & $12(70.6)(\mathrm{n}=17)$ & $15(35.7)$ & $5.929^{\star}$ \\
\hline Bromocriptine & $1(8.3)(n=17)$ & $4(9.5)$ & \\
\hline DA agonist & $13(76.5)(n=17)$ & $18(42.9)$ & $5.490^{\star}$ \\
\hline Anticholinergics & $2(16.7)$ & $9(21.4)$ & 0.002 \\
\hline Selegiline & $4(33.3)$ & $11(26.2)$ & 0.015 \\
\hline Apomorphine & $1(8.3)$ & $2(4.8)$ & \\
\hline Untreated & 0 & $1(2.4)$ & \\
\hline
\end{tabular}

${ }^{\star} \mathrm{P}<0.05 ;{ }^{\star \star} \mathrm{P}<0.01$.

function (BDS; $t=2.80, \mathrm{P}<0.05)$ and letter fluency $(t=2.81, \mathrm{P}<0.05)$ than the non-hallucinators. The groups did not differ on any other measures of memory or executive function (table 2). The mood of late non-hallucinators was significantly more depressed than that of the hallucinators (BDI; $t=3.06, \mathrm{P}<0.05$ ). Figure 4 shows the global cognitive, letter fluency, and mood scores of the hallucinators and nonhallucinators.

The frequency of occurrence of complications of the disease and the duration of idiopathic Parkinson's disease at the onset of complications were compared between the late hallucinators and non-hallucinators. There was no difference between late hallucinators and non-hallucinators in the duration of idiopathic

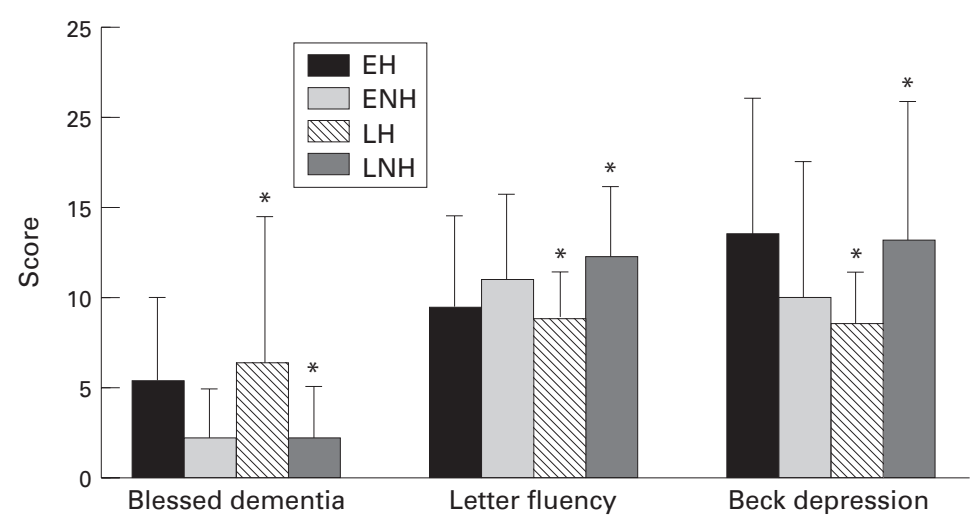

Figure 4 Global cognitive, letter fluency, and mood scores. EH=early hallucinators;

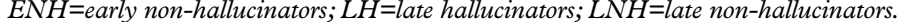
${ }^{\star} P<0.05$. High global cognitive and mood scores represent impairment, whereas a high letter fluency score represents good performance.
Parkinson's disease at the onset of any disease complication. Figure 2 shows that the hallucinators had experienced loss of balance when turning significantly more than the nonhallucinators $\left(\chi^{2}=10.55, \mathrm{P}<0.01\right)$. However, the groups did not differ in the occurrence of falls $\left(\chi^{2}=0.03, \mathrm{P}<0.90\right)$, response fluctuations $\left(\chi^{2}=0.01, \mathrm{P}<0.95\right)$, or involuntary movements $\left(\chi^{2}=0.03, \mathrm{P}<0.90\right)$.

The proportion of late hallucinators and non-hallucinators taking each class of dopaminergic medication was compared. Only one non-hallucinating patient was unmedicated and the frequency of prescription of apomorphine and bromocriptine were too small for statistical comparison. Patients with and without hallucinosis did not differ in the frequency with which they took levodopa $\left(\chi^{2}=0.74, \quad P<0.50\right), \quad$ anticholinergic drugs $\left(\chi^{2}=0.002, \mathrm{P}<0.95\right)$, and selegiline $\left(\chi^{2}=0.02\right.$, $\mathrm{P}<0.90)$. Figure 3 shows that late hallucinators were significantly more likely to be treated with a direct acting dopamine agonist (pergolide or bromocriptine, $\left.\chi^{2}=5.49, \quad \mathrm{P}<0.05\right)$ than the non-hallucinators, as was the case for pergolide alone $\left(\chi^{2}=5.93, P<0.05\right)$. There was no difference between the hallucinators and nonhallucinators in the daily dose of levodopa $(t=0.50, \mathrm{P}<0.62)$ or dopamine agonist $(t=0.07$, $\mathrm{P}<0.95)$. The number of dopaminergic medications received did not differ between groups $(t=0.72, \mathrm{P}<0.47)$.

\section{Discussion}

Patient selection was controlled through the strict application of the Parkinson's Disease Society brain bank clinical diagnostic criteria for idiopathic Parkinson's disease. We were aware that inclusion of patients with clinically overt cortical Lewy body disease could affect the results and have minimised this bias as far as possible by excluding those with atypical disease onset, fluctuating confusion, or hallucinosis before treatment with dopaminergic medication.

Hallucinosis, encompassing both true hallucinations and illusions, occurred in about $25 \%$ of patients with idiopathic Parkinson's disease, a prevalence in agreement with previous estimates. ${ }^{1}$ The primary modality for hallucinosis was visual although, in agreement with others, a secondary auditory component was present in over $40 \% .{ }^{2}$ Generally the hallucinatory experiences were recognisable images of static people, often strangers, or small animals, which occurred on a background of a clear sensorium. Pure auditory hallucinosis was found in only two cases. A fifth of the patients reported paranoid ideation during hallucinosis and, when fear was present, it was often confined to the initial hallucinatory experience. The stereotyped theme to hallucinations, combined with the passivity of the experiences, may account for the lack of concern expressed by most patients.

Contrary to previous findings, hallucinosis did not occur predominantly during the later stages of idiopathic Parkinson's disease, ${ }^{38}{ }^{8}$ nor did its prevalence increase on a continuum throughout the course of the disease. ${ }^{102526} \mathrm{~A}$ 
peak in the initial occurrence of hallucinosis was found within the first five years of idiopathic Parkinson's disease, superimposed on an otherwise increasing prevalence of onset of hallucinosis with duration of disease. We interpreted this as the existence of two distinct subgroups which we defined as early hallucinators with onset at, or before, five years of disease and late hallucinators with onset after five years of disease.

The early hallucinators did not differ from the non-hallucinators for age at disease onset, motor disability when "on", cognitive function, dosage of levodopa, or dopamine agonist medications. However, the hallucinators were prescribed a greater total number of dopaminergic medications than the non-hallucinators, which is a reflection of the high proportion of non-hallucinators receiving no dopaminergic replacement. Motor complications of disease were more likely to be experienced by early hallucinators than non-hallucinators. The duration of idiopathic Parkinson's disease at the onset of response fluctuations was also shorter in the early hallucinators than in the nonhallucinators. We suggest that the short time to onset and the greater prevalence of motor complications in the early hallucinators reflects a more rapid progression of idiopathic Parkinson's disease than in the non-hallucinators.

The coexistence of involuntary movements and hallucinosis has been found previously and explained as a state of denervation supersensitivity of the dopamine receptors in both the mesolimbic/mesocortical and nigrostriatal systems. ${ }^{4627}$ It is suggested that when insufficient dopamine is supplied by the presynaptic neurons of these systems due to neuronal degeneration, the postsynaptic membrane develops an increased number, or sensitivity, of receptors. Artificial dopamine replacement, whether through treatment with the precursor levodopa or through direct acting agonists, then leads to overstimulation resulting in involuntary movement from the nigrostriatal system and hallucinosis from the mesolimbic/ mesocortical system. Therefore, the susceptibility to early hallucinosis may be caused by more advanced denervation supersensitivity in the mesolimbic/mesocortical system of this subgroup.

Our subgroup of hallucinators whose initial hallucinosis occurred after a disease duration of five years are probably similar to the chronically medicated hallucinating patients previously reported by other groups. ${ }^{313} 14$ The hallucinators and non-hallucinators in this group did not differ for age at onset of disease, quantity of daily dopaminergic medication, or motor disability when "on". There was a high prevalence of dopamine responsive motor complications in both the late hallucinators and non-hallucinators. The onset of these complications occurred at a similar duration of disease for both groups, which suggests comparable dopaminergic pathology. The late hallucinators were more likely to lose their balance when turning than the non-hallucinators. Postural instability is a complication of Parkinson's disease which is not mediated by dopaminergic receptors and it is possible that this feature reflects pathology outside the basal ganglia in, for example, the cerebral cortex. Consistent with this idea and, confirming recent findings of inferior cognitive performance in hallucinators with idiopathic Parkinson's disease, ${ }^{8} 928$ our late hallucinators were significantly more impaired in global cognitive function and in letter fluency than the non-hallucinators. The cortical changes underlying late hallucinosis and the associated cognitive deficits may include diffuse cortical Lewy body pathology, and concomitant Alzheimer's disease or vascular pathology. ${ }^{29}$

Although global cognitive and letter fluency performance was inferior in the late hallucinators, the cognitive realms of recognition memory, working memory, and executive function were similar for the two groups. This cognitive profile found in the late hallucinators may be accounted for, at least in part, by the experimental design. The more cognitively impaired patients were able only to complete the simpler cognitive assessments in the battery such as the measure of global cognitive function and the letter fluency assessment. Therefore, the extent of cognitive impairment on the more demanding tasks may be underrepresented in this group.

The late hallucinators and non-hallucinators differed in affective disorder, the non-hallucinators being significantly more depressed. Affective disorder has been linked to low concentrations of serotonin (5-HT) turnover in the brain. ${ }^{30}$ This is consistent with the hypothesis that hallucinosis in idiopathic Parkinson's disease of longer duration may be associated with a relatively overactive serotonergic system. Two other circumstantial pieces of evidence support the involvement of 5-HT in hallucinosis in idiopathic Parkinson's disease. Firstly, the finding that 5-HT reuptake inhibitors can induce psychosis ${ }^{31}$ and secondly, the relief of hallucinosis in idiopathic Parkinson's disease by the atypical neuroleptic drugs ondansetron, ${ }^{14}$ clozapine, ${ }^{32}$ and olanzapine, ${ }^{33}$ which have $5-\mathrm{HT}$ antagonist properties. Chronic dopamine replacement lowers brainstem 5-HT concentrations, which leads to postsynaptic 5-HT receptor denervation supersensitivity. Stimulation of these sensitive receptors may then result in hallucinosis. ${ }^{7}$

Another explanation of this result is that methodology may have been responsible for the difference in affective disorder of the late hallucinators and non-hallucinators. Patients' self-reporting becomes increasingly unreliable with advancing cognitive impairment ${ }^{34}$ and the lack of depressive symptomatology described by the late hallucinators may be due to underreporting rather than to pathophysiological alteration. If the reporting of hallucinosis was also affected in a similar manner, the magnitude of the late hallucinators' cognitive deficit would have been underestimated in this report.

A consistent finding distinguishing both early and late hallucinators from the nonhallucinators was the significantly greater proportion treated with a direct acting dopamine receptor agonist. The same finding 
was also reported by Cummings ${ }^{1}$ after a review of several studies of hallucinosis in Parkinson's disease. Medication with dopamine receptor agonists is often introduced to manage the motor complications which occur in patients with idiopathic Parkinson's disease. However, in our group of late hallucinators at least, there was not an increased proportion of patients experiencing these motor complications. We propose two possible explanations for the increased risk of hallucinosis in patients with idiopathic Parkinson's disease treated with a dopamine receptor agonist. Firstly, the presynaptic dopaminergic neurons of the mesolimbic/ mesocortical system may degenerate faster than those of the nigrostriatal system in hallucinators. Levodopa would therefore produce motor control without hallucinosis. However, when the postsynaptic receptors are stimulated directly with dopamine agonist therapy, motor control is achieved at the expense of excessive stimulation of the supersensitive postsynaptic receptors of the mesolimbic/mesocortical system resulting in hallucinosis. Alternatively, there are different dopamine receptor subtypes, one or several of which may be of particular importance in the aetiology of hallucinosis. The increased prevalence of hallucinosis with dopamine agonists may be due to greater stimulation of certain dopamine receptor subtypes. The propensity to develop hallucinosis in some patients would then reflect phenotypic differences in dopamine receptor type or distribution.

In summary, we have identified two subgroups susceptible to hallucinosis in idiopathic Parkinson's disease. Patients with a disease duration of five years or less are at risk of developing hallucinosis without cognitive impairment if there is an early appearance of motor complications. Postsynaptic dopamine receptor denervation supersensitivity in the mesolimbic/mesocortical system may underlie hallucinosis in this group. Patients with a disease duration greater than five years are at risk of developing hallucinosis with cognitive impairment associated with postural instability and a lack of depressive affect. Hallucinosis in this subgroup may be mediated either by changes outside the basal ganglia or by the serotonergic system. Direct acting dopamine agonist medications seem to increase the risk of developing hallucinosis in patients with idiopathic Parkinson's disease. The responses of these subgroups to treatment of hallucinosis may be different.

1 Cummings JL. Behavioral complications of drug treatment of Parkinson's disease. F Am Geriatr Soc 1991;39:708-16.

2 Sanchez-Ramos JR, Ortoll R, Singer C, Schulman L, Weiner WJ, Paulson G. Visual hallucinations in Parkinson's disease [abstract]. Ann Neurol 1993;34:264-65.

3 Goetz CG, Tanner CM, Klawans HL. Pharmacology of hallucinations induced by long-term drug therapy. Am $\mathcal{F}$ Psychiatry 1982;139:494-7.

4 Moskovitz C, Moses H, Klawans HL. Levodopa-induced psychosis: a kindling phenomenon. Am $\mathcal{f}$ Psychiatry 1978;135:669-75.

5 Klawans HL. Levodopa induced psychosis. Psychiatric Annals 1978;8:447-51.

6 Factor SA, Molho ES, Podskalny GD, Brown D. Parkinson's disease: drug-induced psychiatric states. Adv Neurol 1995; 65:115-38.
7 Nausieda PA, Weiner WJ, Kaplan LR, Weber S, Klawans HL. Sleep disruption in the course of chronic levodopa
therapy: an early feature of the levodopa psychosis. Clin therapy: an early feature of the

8 Vieregge P, Klein C, Pulkowski U, Kompf D. Visual hallucinations in Parkinson's disease: a controlled study. Mov Disord 1996;11 (suppl 1):158.

9 Kippervasser S, Inzelberg R, Korczyn AD. Auditory hallucinations in Parkinson's disease. Mov Disord 1996;11(suppl 1): 194 .

10 Danielczyk W. Mental disorders in Parkinson's disease. $\mathcal{f}$ Neural Transm Suppl 1992;38:115-27.

11 Fischer P, Danielczyk W, Simanyi M, Streifler MB. Dopaminergic psychosis in advanced Parkinson's disease. Adv Neurol 1990;53:391-7.

12 Meco G, Bonifati V, Cusimano G, Fabrizio E, Vanacore N. Hallucinations in Parkinson's disease: neuropsychological study. Ital f Neurol Sci 1990;11:373-9.

13 Rondot P, de Recondo J, Coignet A, Ziegler M. Mental disorders in Parkinson's disease after treatment with L-dopa. Adv Neurol 1984;40:259-69.

14 Zoldan J, Friedberg G, Livneh M, Melamed E. Psychosis in advanced Parkinson's disease: treatment with ondansetron, a 5-HT3 receptor agonist. Neurology 1995;45:1305-8.

15 Daniel SE, Lees AJ. Parkinson's Disease Society brain bank, London: overview and research. $\mathcal{F}$ Neural Transm 1993; 39(suppl):165-72.

16 Fahn S, Elton RL, members of the UPDRS Development Committee. The unified Parkinson's disease rating scale. In: Fahn S, Marsden CD, Calne DB, Goldstein M, eds. Recent developments in Parkinson's disease. Vol 2. Florham Park, NJ: Macmillan Healthcare Information, 1987:15363; 293-304.

17 Beck AT, Ward CH, Mendelson M, Mock J, Erbaugh J. An inventory for measuring depression. Arch Gen Psychiatry 1961;4:561-71

18 Nelson HE, O'Connell A. Dementia: the estimation of premorbid intelligence levels using the new adult reading test. Cortex 1978;14:234-44.

19 Blessed G, Tomlinson BE, Roth $M$. The association between quantitative measures of dementia and of senile change in the cerebral grey matter of elderly subjects. $B r f$ change in the cerebral grey matt
Psychiatry 1968;114:797-811.

20 Thurstone LL. Primary mental abilities. Chicago: University of Chicago Press, 1938.

21 Sahakian BJ, Morris RG, Evenden JL, Heald A, Levy R, Philpot $\mathrm{M}$, et al. A comparative study of visuospatial memory and learning in Alzheimer-type dementia and Parkinson's disease. Brain 1988;111:695-718.

22 Owen AM, Downes JJ, Sahakian BJ, Polkey CE, Robbins TW. Planning and spatial working memory following frontal lobe lesions in man. Neuropsychologia 1990a;28:102134.

23 Cooper JA, Sagar HJ, Jordan N, Harvey NS, Sullivan EV. Cognitive impairment in early, untreated Parkinson's disease and its relationship to motor disability. Brain 1991; 114:2095-122.

24 Downes JJ, Roberts AC, Sahakian BJ, Evenden JL, Morris RG, Robbins TW. Impaired extra-dimensional shift performance in medicated and unmedicated Parkinson's disease: evidence for a specific attentional dysfunction. Neuropsychologia 1989;27:1329-43.

25 Roos RAC. Dopaminomimetic psychosis: clinical manifestations, epidemiology and risk factors. In: Wolters EC, Scheltens P, eds. Mental dysfunction in Parkinson's disease. Dordrecht, The Netherlands: ICG Publications, 1994: 281-4.

26 Tanner CM, Vogel C, Goetz CG, Klawans HL. Hallucinations in Parkinson's disease: a population study. Ann Neurol 1983;14:136.

27 Wolters EC, Kuiper MA, Zwaan WA, Horstink MWIM, Scheltens P. Dopaminomimetic psychosis: therapeutic strategies. In: Wolters EC, Scheltens P, eds. Mental dysfunction in Parkinson's disease. Dordrecht, The Netherlands: ICG Publications, 1994:285-95.

28 Sanchez-Ramos JR, Ortoll R, Paulson GW. Visual hallucinations associated with Parkinson's disease. Arch Neurol 1996;53:1265-8.

29 Sagar HJ. Psychopharmacology of cognitive impairment in Parkinson's disease. In, Perry RH, McKeith IG, Perry EK, eds. Dementia with Lewy bodies: clinical, pathological, and treatment issues. Cambridge: Cambridge University Press, 1996:363-80.

30 Van Praag HM. Serotonin and affective psychopathology in Parkinson's disease. A psychobiological hypothesis with therapeutic consequences. In: Wolters EC, Scheltens P, eds. Mental dysfunction in Parkinson's disease. Dordrecht, The Netherlands: ICG Publications, 1994:335-48.

31 Lauterbach EC. Serotonin reuptake inhibitors, paranoia, and the ventral basal ganglia. Clin Neuropharmacol 1991;14:547-55.

32 Hippius H. The history of clozapine. Psychopharmacology 1989;99:S3-5

33 Wolters ECh, Jansen ENH, Tuynman-Qua HG, Bergmans PLM. Olanzapine in the treatment of dopaminomimetic psychosis in patients with Parkinson's disease. Neurology 1996;47:1085-7.

34 Alexopoulos GS, Abrams RC, Young RC, Shamoian CA. Cornell scale for depression in dementia. Biol Psychiatry 1988;23:271-84. 